\title{
Palabras de clausura del II Simposium Internacional de Castillos
}

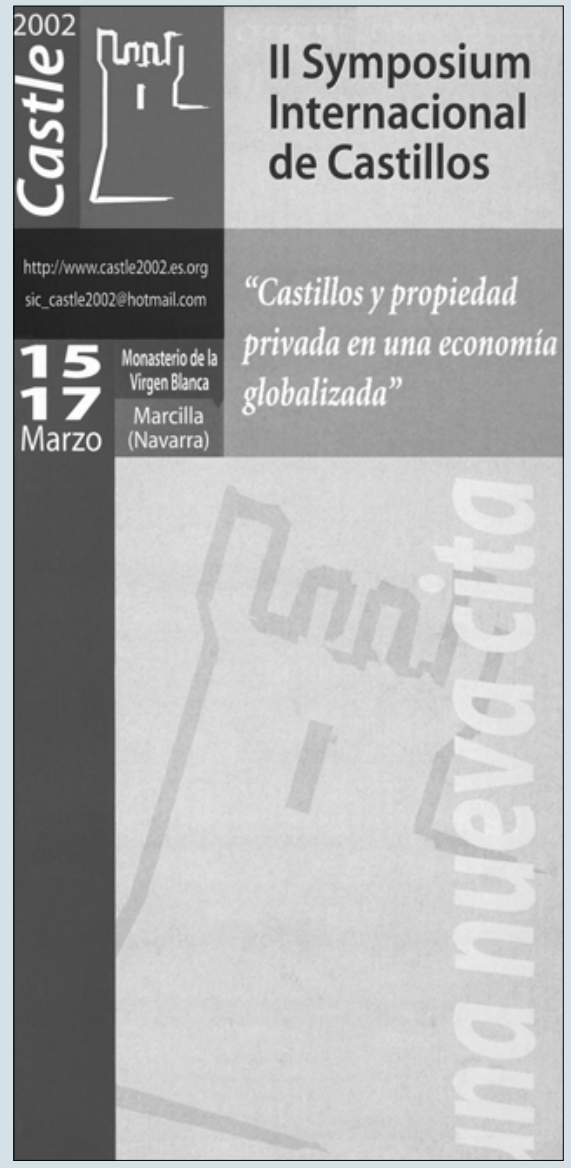

El inicio de un nuevo milenio nos ofrece la oportunidad de ordenar, evaluar y poner en cuestión el tradicional marco de referencia de los castillos, así como de reflexionar, bajo el prisma de la globalización y la "nueva economía", sobre las ideas, factores y elementos, tanto endógenos como exógenos, que pueden modificarlos con viveza. En este sentido, la irrupción de una economía global, fundamentada en la generación y procesamiento de información y la instantaneidad de las comunicaciones, con repercusiones innovadoras en las condiciones de tiempo, espacio y materia de toda actividad económica, permiten a los castillos y sus actividades, que su organización, sus infraestructuras, sus instalaciones, además de sus relaciones con el entorno, puedan verse sometidas a importantes transformaciones en un futuro cercano.

Algunos sectores empresariales, y no son pocos los propietarios de castillos, están tomando conciencia de la potencialidad que ofrecen el desarrollo de las nuevas tecnologías, y fenómenos económicos nuevos como el turismo rural y el turismo cultural. Por ello, están demandando a las diferentes administraciones públicas que apoyen y lideren iniciativas dirigidas a recuperar los edificios, a prestigiarlos de nuevo y a incentivar distintas actividades que los reactiven. No son pocos los que consideran que este inicio de milenio es un buen momento y por tanto que resulta estratégico, que el patrimonio español se abra a otros ámbitos de una forma ordenada y coordinada, con una estrategia clara, definida, con objetivos marcados, que permita explotar, recuperar, conservar, aunando esfuerzos y recursos, en pro del desarrollo y consolidación de una imagen de marca nacional, ligada a la historia, pero íntimamente unida al desarrollo tecnológico, la economía y la calidad de los servicios.

Crear y consolidar esta imagen es el mejor apoyo para estos edificios, y para quienes han asumido iniciativas comerciales, culturales o industriales.

En los últimos años se ha realizado un enorme esfuerzo de participación y presencia activa por parte de instituciones, empresas e iniciativas privadas en distintos ámbitos y formas, que han ido cambiando la visión, aspecto y realidad de estas joyas históricas. Los castillos y fortalezas, por su estructura, número y potencial de desarrollo, así como por los lazos históricos y culturales que les unen al entorno en que se localizan, son cada vez más objetos preferentes para la industria y los servicios. Sin duda, constituyen un mercado nuevo, un novedoso referente, al que pueden dirigirse eficazmente diferentes sectores.

Como ya afirmamos en la primera edición, creo no equivocarme si afirmo que el futuro de los castillos pasa por su actualización a los nuevos tiempos, al tiempo que por la necesidad de ponerse de actualidad. El uso de nuevos métodos de comercialización, el manejo adecuado de las nuevas estrategias de marketing, la utilización correcta de las nuevas tecnologías y más en concreto de internet, unido al desarrollo del sector servicios, léase turismo rural y cultural, deben aportar los elementos sobre los que debe basarse el futuro del patrimonio en general, y de los castillos en particular. En este sentido, a la tradi- cional ayuda institucional debe sumarse la iniciativa privada.

Estas son algunas de las ideas que pueden extraerse de los contenidos de las distintas ponencias presentadas. Todas ellas han incidido en uno u otro aspecto, y nos han presentado experiencias concretas y particulares, unas más exitosas que otras. Pero de todas ellas, puede concluirse que los castillos españoles no tienen problemas particulares. Todos comparten los mismos problemas y deben sortear parecidos obstáculos. En este sentido, haber contribuido a crear un punto de encuentro de todos ellos en Marcilla, es en sí mismo un éxito en esta segunda convocatoria.

José $\mathrm{M}^{\mathrm{a}}$ Cambra Amigot

Presidente "Amigos del Castillo de Marcilla"

El II Simposiun Internacional de Castillos se celebró en Marcilla (Navarra), entre los pasados 15 y 17 de marzo de 2002, bajo el lema "Castillos y propiedad privada en una economía globalizada".

Más información:

Amigos del Castillo de Marcilla

Casa de la Cultura

C/ San Bartolomé, 8-3

31340 Marcilla, Navarra

Tel.: 616795226

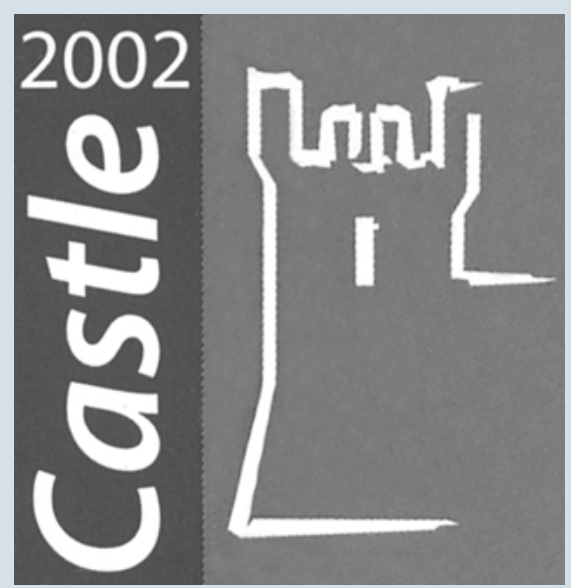

